\title{
ELECTROCARDIOGRAPHIC CHANGES AND THE EFFECT OF NIACIN THERAPY IN PELLAGRA
}

BY

\author{
M. RACHMILEWITZ AND K. BRAUN \\ From the Medical Dept. (Div. B.), Rothschild Hadassah University Hospital, Jerusalem \\ Received November 8, 1945
}

In a previous communication (Rachmilewitz and Braun, 1944), we reported on electrocardiographic changes in patients showing clinical signs of niacin (nicotinic acid) deficiency, which were eliminated by administration of this vitamin: we concluded that they were due to this specific deficiency. Our observations on the effect of niacin on these cardiographic changes have since been extended, and the results of these studies are now reported.

\section{Present Investigation}

Clinical and cardiographic studies were made on 27 patients suffering from pellagra. The outstanding clinical manifestations were those attributable to niacin deficiency such as pellagrous dermatitis, stomatitis, gastro-intestinal disturbances (most frequently diarrhœa), and mental symptoms. In 22 cases there were typical skin lesions of pellagra, varying in degree and intensity; in some the acute erythematous lesions were present, in others there was hyperkeratosis and pigmentation of the exposed parts of the body. In 3 cases no skin changes were present; 3 other patients had had typical pellagra dermatitis on previous occasions, but not at the time when the studies were made. In these 6 cases the diagnosis of the deficiency state was based on glossitis and on gastro-intestinal and mental disturbances. In addition to the diagnostic features of niacin deficiency, some cases of the entire group also exhibited signs of ariboflavinosis, such as, cheilosis, angular stomatitis, and corneal vascularization. In 10 of the cases there was also evidence of thiamin $\left(B_{1}\right)$ avitaminosis consisting of pain in the calf muscles, para-æsthesia, muscular weakness, and cramps, as well as objective findings indicating peripheral neuritis and sometimes also pyramidal involvement.

No one of the cases included in this report had obvious disturbances of the cardiac function and no one was suffering from heart failure as seen in beriberi heart. When œdema of the lower extremities. was present it was associated with hypoproteinæmia, but was obviously not due to cardiac insufficiency. The subjective complaints of the patients referable to the heart were insignificant; only a few patients experienced a feeling of oppression and palpitation. Corresponding to the poor general condition of the patients and the state of malnutrition, the blood pressure on admission was usually below normal, and increased gradually with the clinical improvement. There were no striking deviations in the pulse pressure. The pulse rate, before the specific treatment, varied from 37 to 110, ranging in most from 60 to 80 , and scarcely changed after the specific treatment. In the few cases with a rapid pulse, it became slower after treatment. In one case a bradycardia of 37 beats a minute disappeared with recovery.

Clinical and X-ray examinations showed the heart to be normal or sometimes subnormal in size. In a small number of cases circulation time and venous pressure estimations were made and normal values were observed.

Cardiographic tracings were taken before treatment and at frequent intervals following various therapeutic procedures, consisting of individual vitamins of the $B$ complex. Since we were concerned particularly with the differentiation of the effect of niacin from that of thiamin, a number of the cases were put on a vitamin $\mathbf{B}_{1}$ poor diet, while receiving niacin, while in others vitamin $B_{1}$ was given during a certain control period before the institution of niacin treatment. 
Group 1. Cases with Prompt Response to Niacin

This group comprises 16 patients, all with cardiographic changes of varying degrees and intensity before treatment. The age of these patients ranged from 16 to 65 , the majority being below 50. The most striking changes were frequently seen in the younger patients, but the response to treatment was equally effective in the older patients. The cardiographic changes were manifested mainly on the final deflection: alterations of the S-T segment or of the $\mathrm{T}$ wave were present in all those with abnormal records. $\mathrm{S}-\mathrm{T}$ depression in at least two limb leads was present in 9 cases; in $4 \mathrm{~S}-\mathrm{T}$ was below the isoelectric line in one lead only. Abnormalities of the $\mathrm{T}$ wave in at least two leads were present in the entire group of cases; the $\mathrm{T}$ waves were negative, absent, diphasic, or flattened. In all except three, chest leads (CF ) were taken. Out of these 13 records with chest leads 10 showed negative or flat $\mathrm{T}$ waves. The ventricular complexes, the $\mathrm{P}$ waves, and the $\mathrm{P}-\mathrm{R}$ intervals were practically normal in all the records.

In all cases the response to niacin treatment was an improvement of the cardiogram. The positive effect was usually seen after 4-5 days of treatment, which consisted of niacin by mouth in daily doses of 300 to $500 \mathrm{mg}$. Only occasionally, in patients suffering from severe diarrhœa or vomiting, the peroral administration was supplemented by intravenous injections of 50 to $100 \mathrm{mg}$. daily. In most cases the optimal effect was obtained after 3 to 5 days and remained so after discontinuation of the medication. In some cases, however, the treatment had to be continued because of incomplete improvement and in these a normal curve was obtained after continuing the treatment for another 10 to 14 days. The cardiographic and clinical improvement were not always parallel, and a normal pattern was frequently obtained when the dermatitis and the changes in the mouth and gastrointestinal tract were still present.

The pathological character of the cardiogram disappeared usually simultaneously in all leads and the improvement was most striking where the changes had been the most prominent. The S-T depression disappeared and the $\mathrm{T}$ waves became positive or more elevated.

Table I shows the changes that took place as the result of the treatment. The degree

TABLE I

\begin{tabular}{|c|c|c|c|c|}
\hline \multirow{2}{*}{$\begin{array}{l}\text { Case } \\
\text { No. }\end{array}$} & \multirow{2}{*}{$\begin{array}{l}\text { Sex } \\
\text { and } \\
\text { Age }\end{array}$} & \multirow{2}{*}{$\begin{array}{c}\text { Pulse } \\
\text { on } \\
\text { admis- } \\
\text { sion }\end{array}$} & \multicolumn{2}{|c|}{ Electrocardiographic findings } \\
\hline & & & Before treatment & After treatment \\
\hline 1 & F. 30 & 80 & $\begin{array}{l}\text { T I absent, T II, T III, T IV negative, de- } \\
\text { pression of S-T (II, III) }\end{array}$ & $\begin{array}{l}\text { T I, T II upright, T III, T IV absent, S-T } \\
\text { (II, III) isoelectric }\end{array}$ \\
\hline 2 & M. 50 & 37 & $\begin{array}{l}\text { T I absent, T II, T III diphasic, depres- } \\
\text { sion of S-T (II, III) }\end{array}$ & $\begin{array}{l}\text { T I, T II, T III, T IV upright, normal, S-T } \\
\text { (II, III) isoelectric }\end{array}$ \\
\hline 3 & M. 65 & 66 & $\begin{array}{l}\text { Extrasystoles, T I absent, T II, T III slightly } \\
\text { negative, depression of S-T (II, III) }\end{array}$ & $\begin{array}{l}\text { Sinus rhythm, T I absent, T II, T III posi- } \\
\text { tive, S-T (II, III), isoelectric }\end{array}$ \\
\hline 4 & F. 25 & 110 & $\begin{array}{l}\text { T II flat, T III absent, depression of S-T } \\
\text { (I, II, III) }\end{array}$ & $\begin{array}{l}\text { T II upright } \\
\text { isoelectric }\end{array}$ \\
\hline 5 & F. 50 & 80 & T I, T II flat, depression of S-T (I, II, III) & T I upright +, S-T (I, II, III) isoelectric \\
\hline 6 & F. 51 & 80 & $\begin{array}{l}\text { T I flat, T IV negative, depression of S-T } \\
\text { (I, II, IV) }\end{array}$ & $\begin{array}{l}\text { T II upright }++, \text { T III upright }++, \mathrm{T} \text { IV } \\
\text { positive }\end{array}$ \\
\hline 7 & M. 50 & 85 & $\begin{array}{l}\text { T I, T II, T III, T IV flat, depression of } \\
\text { S-T (II) }\end{array}$ & $\begin{array}{l}\text { T II upright }++, \text { T III upright }++, \text { T IV } \\
\text { upright }++, \text { S-T (II) isoelectric }\end{array}$ \\
\hline 8 & F. 45 & 60 & $\underset{\text { phasic }}{\text { T II flat, T III negative, T IV di- }}$ & $\begin{array}{l}\text { T I upright }+ \text {, T II upright }++, \text { T III } \\
\text { positive, T IV upright }++\end{array}$ \\
\hline 9 & M. 50 & 58 & $\begin{array}{l}\text { T I absent, T II, T III flat, depression of } \\
\text { S-T (II) }\end{array}$ & $\begin{array}{l}\text { T I positive, } \mathrm{T} \text { II upright }+, \mathrm{S}-\mathrm{T} \text { (II) iso- } \\
\text { electric }\end{array}$ \\
\hline 10 & F. 45 & 80 & $\begin{array}{l}\text { T I flat, diphasic, T III negative, TII, T IV } \\
\text { flat, depression of S-T (I, II) }\end{array}$ & $\begin{array}{l}\text { T I upright }+, \text { T II upright }++, \text { T III posi- } \\
\text { tive, T IV upright }+, S-T(I, I I) \text { isoelectric }\end{array}$ \\
\hline 11 & M. 58 & 62 & $\begin{array}{l}\text { T I, T II, T III, T IV flat, S-T (I) above } \\
\text { zero level, S-T (II) depressed }\end{array}$ & $\begin{array}{l}\text { T I upright }+, \text { T II upright }++ \text {, T IV up- } \\
\text { right }++, \text { S-T (I, II) isoelectric }\end{array}$ \\
\hline 12 & M. 20 & 80 & $\begin{array}{l}\text { T I flat, diphasic, T II flat, T III, T IV ab- } \\
\text { sent, depression of S-T (I, II) }\end{array}$ & $\begin{array}{l}\text { T I, T II, T IV upright }+, \text { S-T (I, II) iso- } \\
\text { electric }\end{array}$ \\
\hline 13 & F. 30 & 52 & T I, T II flat, diphasic, T IV negative & $\underset{\text { negative }}{\mathrm{T} \mathrm{I}}$ upright + T II upright,$++ \mathrm{T}$ IV \\
\hline 14 & M. 26 & 80 & $\begin{array}{l}\text { T I absent, T II, T III flat, depression of } \\
\text { S-T (II, III) }\end{array}$ & T I flat, T II upright.++ , T III upright \\
\hline 15 & F. 60 & 58 & $\begin{array}{l}\text { T I, T II, T III flat, T IV negative, S-T } \\
\text { (II, III) elevated }\end{array}$ & $\begin{array}{l}\text { T I upright }+, \text { T II upright }++ \text {, T III up- } \\
\text { right }+, T \text { IV positive, diphasic, S-T (II, } \\
\text { III) elevated }\end{array}$ \\
\hline 16 & M. 16 & 85 & $\begin{array}{l}\text { T I, T II, T IV flat, T III negative, depres- } \\
\text { sion of S-T (I) }\end{array}$ & $\begin{array}{l}\text { T I upright }+, \text { T II upright }+, \text { T III nega- } \\
\text { tive, } \mathrm{T} \text { IV upright }++, \mathrm{S}-\mathrm{T} \text { (I) isoelectric }\end{array}$ \\
\hline
\end{tabular}


of elevation of the $\mathrm{T}$ waves following niacin administration was designated as + corresponding to an elevation of $0.5 \mathrm{~mm} . \pm 0.25 \mathrm{~mm}$; as ++ corresponding to an elevation of $1 \mathrm{~mm}$. \pm 0.25 ; and as +++ corresponding to an elevation of $1.5 \mathrm{~mm}$. $\pm 0.25 \mathrm{~mm}$.

The following are a few typical case histories.

Case 6. A woman of 51 was first seen in the out-patient department 18 months before her admission to hospital. She then had pellagrous dermatitis for which niacin was prescribed. She discontinued treatment because of a burning sensation in the skin following the intake of the drug. During this time she complained of general weakness and poor appetite, and mental disturbances appeared-irritability, depression, and defects of memory. A fortnight before admission, she started a temperature which continued for 10 days and was accompanied by diarrhœa. Subsequently her mental condition deteriorated rapidly and for this reason she was admitted on 8/12/42.

On admission she was disorientated, restless and confused, and there was no control of fæces and urine. Slight pellagrous changes were seen on the back of both hands. The tongue, lips, and gums were bright red and sore. In addition, angular stomatitis as well as seborrhœic accumulations in the naso-labial folds were present. The reflexes of the upper and lower extremities were exaggerated and there was a right patellar clonus and positive Babinski and Oppenheim on the same side.

Laboratory findings. Urine and stools, normal. Blood picture: $\mathrm{Hb} .12 .5 \mathrm{~g}$; red blood cells 3,600,000; white blood cells 7,600 with a normal differential count. Blood chemistry: urea $31 \cdot 5 \mathrm{mg}$, sugar $92 \mathrm{mg}$., $\mathrm{NaCl} 598 \mathrm{mg}$., total protein 5.74 g., albumin 4.30 g., each per 100 c.c. Pyruvic acid in the urine $174 \mathrm{mg}$. The examination of the gastric juice after a caffeine test-meal and histamine injection revealed complete achylia.

Physical examination of the heart showed normal findings; pulse rate 80, blood pressure 110/90. Fig. 1A, taken on Dec. 9, showed a depressed S-T interval in the first, second, and fourth leads and a negative $T$ wave in the fourth lead. Treatment with niacin was started on Dec. 9; $500 \mathrm{mg}$. by mouth and $50 \mathrm{mg}$. intravenously were given daily. After three days a marked change in the patient's mental condition took place. She became coherent, orientated, and began to eat. Control of urine and fæces was also regained. Four days after the start of treatment Fig. 1B showed improvement; S-T II became less depressed, the T waves in the three limb leads became more elevated and a positive $T$ wave appeared in the fourth lead. After continuous treatment with niacin the spastic state of the extremities gradually improved and the clonus disappeared.

Case 7. A 50 year old man, of poor social condition, was brought to the hospital on 5/11/42, in a state of mental stupor which, according to information obtained from relatives, was of 5 days'

I

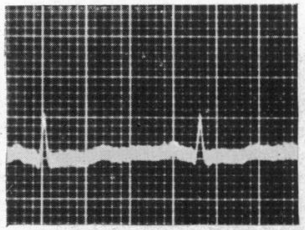

II

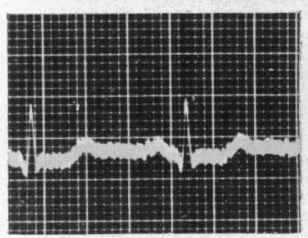

III
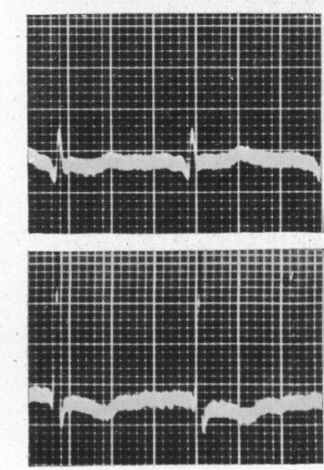

A

Fig. 1.-Case 6. (A) Before treatment. days of niacin treatment.
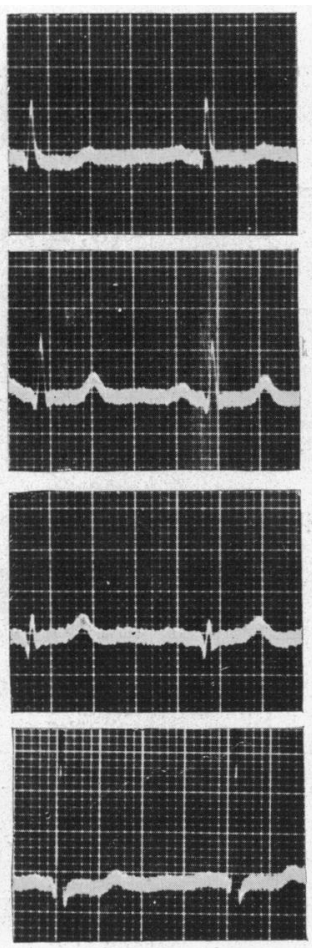

B

(B) After 4
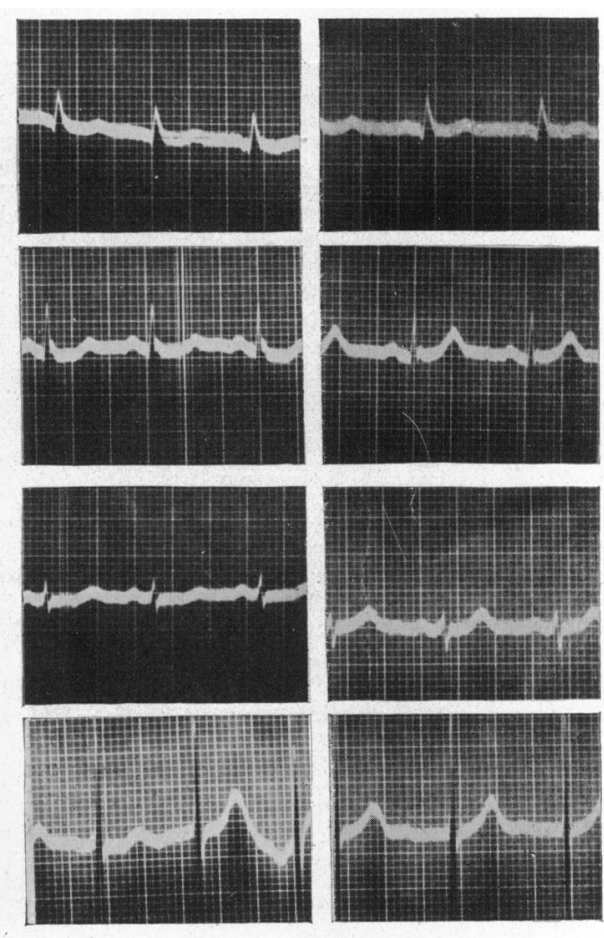

A

FIG. 2.-Case 7. (A) Before treatment. 5 days of niacin treatment. 
duration. The acute illness was preceded by vomiting and severe diarrhœa persisting during 3 weeks. The patient, on admission, was incoherent, and there was no control of urine and fæces. There was marked emaciation and slight œdema of the lower extremities; no evidence of pellagra dermatitis was present, except for slight hyperkeratosis with pigmentation on the back of the feet and hands. The patient exhibited signs of stomatitis and cheilosis. The reflexes of the lower extremities were decreased.

Laboratory findings. Urine: trace of albumin, a number of pus cells in the sediment, and the culture positive for Staph. aureus. The stool contained ova of ascaris. Blood picture: Hb. 70 per cent; red blood cells 2,700,000; white blood cells 8,400 with a normal differential count. Blood urea $35 \mathrm{mg}$., $\mathrm{NaCl} 650 \mathrm{mg}$., sugar $86 \mathrm{mg}$., total protein $5.76 \mathrm{~g}$., albumin $3.8 \mathrm{~g}$., vitamin $\mathrm{C} 0.4 \mathrm{mg}$., each per 100 c.c. Pyruvic acid in the urine $153 \mathrm{mg}$.

The clinical examination revealed normal findings in the heart, which was not enlarged. Pulse rate 85 , blood pressure $105 / 70$. Fig. $2 \mathrm{~A}$, taken immediately after admission, and also 24 hours later after parenteral administration of 2 litres of physiological saline solution, showed S-T depression in the second lead and low positive $T$ waves in all leads. From November 6 to 11 , niacin was given, $500 \mathrm{mg}$. daily by mouth and $100 \mathrm{mg}$. intramuscularly. Two days after beginning of treatment the mental state began to clear up, the patient began to eat and regained control of urine and fæces. This improvement continued during the following days. Fig. 2B, taken November 11, showed S-T II isoelectric and marked elevation of T II, T III, and T IV.

Case 8. A 45 year old woman, with a history of chronic amœbiasis and repeated attacks of diarrhœa, especially during the hot summer months. The first appearance of pellagra dermatitis was noted three years ago. Since then, each attack of diarrhoea was followed by a burning sensation in the tongue and lips as well as by dermatitis on the back of both hands. On 22/7/43, the patient was admitted to hospital, presenting clinical symptoms of pellagra of two months' duration. There were digestive disturbances and psychic changes. The patient also complained of pain in the arms and legs, but no abnormal neurological findings were obtained. No œdema was noted.

Laboratory findings. The stool contained Entameba histolytica. The gastric juice analysis showed complete absence of free hydrochloric acid following caffeine by mouth and histamine injection. The blood picture : Hb. 9.25; red blood cells 3,600,000. Blood chemistry: urea $21 \mathrm{mg}$., sugar $81 \mathrm{mg}$., ascorbic acid $0.6 \mathrm{mg}$., each per 100 c.c. Pyruvic acid in the urine $190 \mathrm{mg}$.

The clinical findings of the heart were essentially normal and there were no signs of heart failure; the pulse rate was 60 and the B.P. 115/70. A cardiogram, taken on July 24, showed low positive T waves in leads I and II, T III inverted and T IV diphasic. After three days of niacin medication consisting of daily doses of $350 \mathrm{mg}$., the clinical signs of deficiency began to clear up. A cardiogram, taken on July 27 showed marked elevation T I, T II, the negative T III became slightly positive; the most striking improvement, however, took place in T IV which became high and upright. The same pattern was obtained after continuing treatment with niacin for another week.

\section{Group II. Cases with Delayed Response to Niacin}

In this group, consisting of two patients suffering from severe deficiency of the vitamin B complex, the immediate improvement in the clinical symptoms and in the altered cardiogram following administration of niacin was slight or absent. In addition to the vitamin B deficiency these patients had also appreciable œdema of the lower extremities and ascites due to severe hypoproteinæmia and hypoalbuminæmia.

In the course of treatment the improved absorption and utilization of food in one case and plasma infusion in the second case resulted in a rise of the blood proteins and disappearance of the œdema. Niacin was again administered and was followed by a noticeable improvement of the cardiogram. These cases will be described briefly.

Case 17. A 40 year old woman suffering from repeated attacks of diarrhœa and chronic malnutrition was admitted on 10/12/43 in an extremely poor condition. She was highly emaciated and showed œdema of the lower extremities. The clinical symptoms of vitamin B deficiency were the following: mental deterioration with incontinence of urine and fæces; typical pellagrous dermatitis on the dorsum of both hands, atrophic glossitis, and severe diarrhœa; in addition there were neuritic manifestations, consisting of hyperreflexia and a positive Babinski reflex on the right side. Thus .there was evidence of both niacin and thiamin deficiency. Laboratory examinations revealed a moderate degree of normocytic anæmia and marked hypoproteinæmia with hypoalbuminæia (total protein $4.7 \mathrm{~g}$. , albumin $1.93 \mathrm{~g}$. , each per 100 c.c.

The heart was normal in size with no evidence of failure. There was no pulmonary congestion and no hepatic engorgement. The pulse rate was 60 , the blood pressure 105/65. Fig. 3A, taken on admission, December 10, showed marked abnormalities in all leads, low voltage of the QRS complexes, S-T II and S-T III noticeably depressed, T I and T IV absent, T II and T III low positive. During the following six days the patient was given a diet which contained only $0.5 \mathrm{mg}$. vitamin $\mathrm{B}_{1}$; to this was added niacin $500 \mathrm{mg}$. by mouth and $100 \mathrm{mg}$. intramuscularly daily. This resulted in 
some improvement of the dermatitis and the mental state. The diarrhœa, however, was hardly influenced. Fig. 4B, taken on December 16, showed slight improvement: a small $\mathrm{T}$ wave appeared in the first lead and the S-T depression in leads II and III disappeared. Niacin was then discontinued and for the following twelve days vitamin $B_{1}$ was given, $30 \mathrm{mg}$. daily intramuscularly. At the end of this period no improvement of the clinical condition was noted and the degree of the œdema remained the same. A cardiogram taken on December 28 was practically the same as before. The following fortnight, although no specific treatment was given, was characterized by gradual and steady clinical improvement of the patient and a marked increase in diuresis, which finally resulted in complete loss of the œdema. The subsidence of the diarrhœa and improved absorption of food resulted in an increase of the serum proteins to 6.5. Fig. 3c, taken on January 10, showed slight elevation of the T waves in all leads, the voltage of the $\mathrm{QRS}$ complex remaining the same. During the following six days niacin was given again, the daily medication consisting of $500 \mathrm{mg}$. by mouth
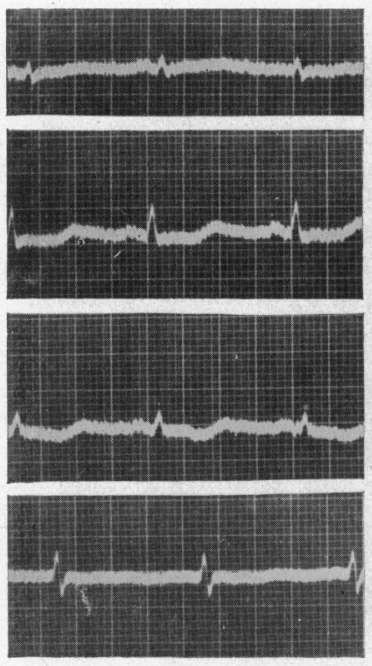

A
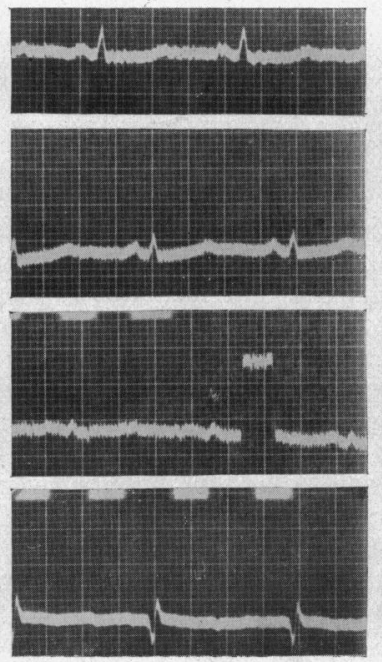

B
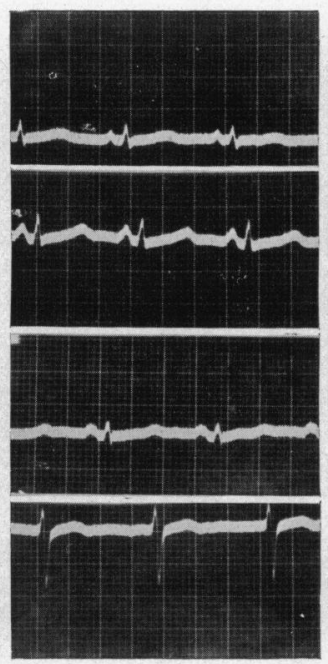

C

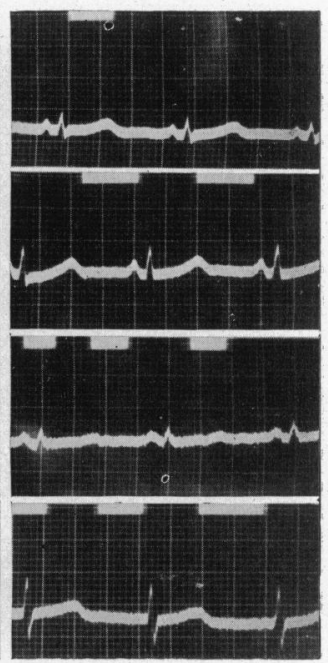

$\mathrm{D}$

FIG. 3.-Case 17. (A) Before treatment. (B) After 6 days of niacin treatment. (C) A fortnight later, after general improvement and increase in serum proteins. (D) After a second course of niacin treatment during 6 days.

and $100 \mathrm{mg}$. intramuscularly. Fig. 3D, on January 16, showed further improvement of the $T$ waves in all four leads without changes in the voltage of the QRS complexes.

In this case, which was characterized by niacin and $\mathbf{B}_{1}$ deficiency and by marked œedema due to hypoproteinæmia, the first trial with niacin produced only slight improvement of the cardiographic pattern; the administration of $\mathbf{B}_{1}$ had no effect. With the gradual amelioration of the general condition of the patient together with better utilization of food, loss of the œdema, and rise in serum proteins there was a gradual improvement. At this last stage, a short course of niacin caused additional improvement of the cardiogram.

Similar observations wele made in Case 18. This was a woman, 30 year old, who had been under treatment in hospital several times during the last three years because of severe pellagra precipitated by excerbations of chronic purulent sinusitis. On last admission, 13/7/43, the patient had fever and severe diarrhœa. The outstanding findings at this time were odema of the lower extremities and ascites, severe atrophic glossitis, and mental changes. The heart was not enlarged on clinical and fluoroscopic examination; the contractions, however, were feeble. There was no distension of the cervical veins and the liver was not enlarged. The pulse rate was 65, B.P. 120/80. The stools contained cysts of Entameba histolytica. The blood picture showed a moderate degree of hypochromic anæmia; blood proteins 3.7 g., albumin 1.3 g., per 100 c.c. Fig. 4 A, 13/7/43, showed marked abnormalities especially of the final deflections of all leads. The first trial with niacin (7 days $500 \mathrm{mg}$. orally and $100 \mathrm{mg}$. intramuscularly), did not produce appreciable changes in the clinical state of the patient, the odema rather increased during this period. Fig. 4B, taken on July 21 , showed. further deterioration, the $T$ waves in the second and third leads becoming slightly negative.

Between July 21 and July 27 , only vitamin $B_{1}$ was given, $40 \mathrm{mg}$. daily intramuscularly. This treatment had no effect on the œdema, the diarrhœe, or the cardiogram. On July 30, a plasma infusion of 400 c.c. was given. Since that date an increase in diuresis took place; this was accompanied by gradual but steady diminution of œdema and ascites. At the same time the diarrhœa markedly diminished in severity and the patient began to eat, the diet containing $70 \mathrm{~g}$. animal proteins per day. On August 7, the total proteins were $5.7 \mathrm{~g}$. and the albumin $3.3 \mathrm{~g}$. per 100 c.c. At this time, another tracing was taken which still showed severe pathological changes. The voltage of the 

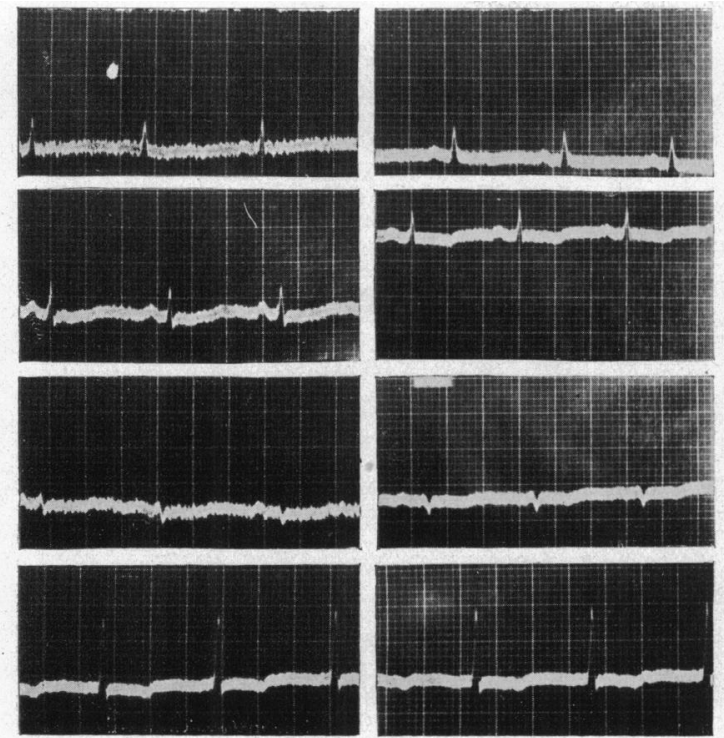

A

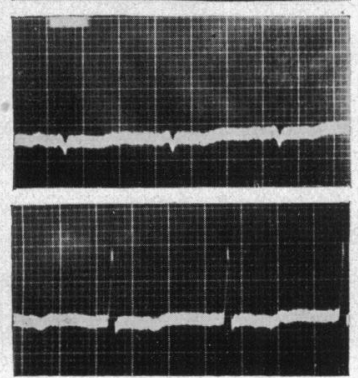

B
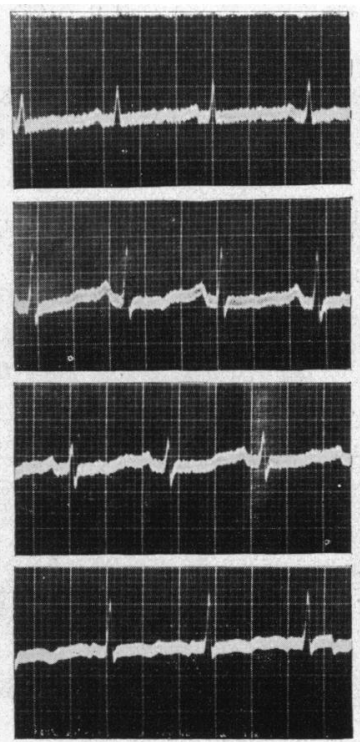

C
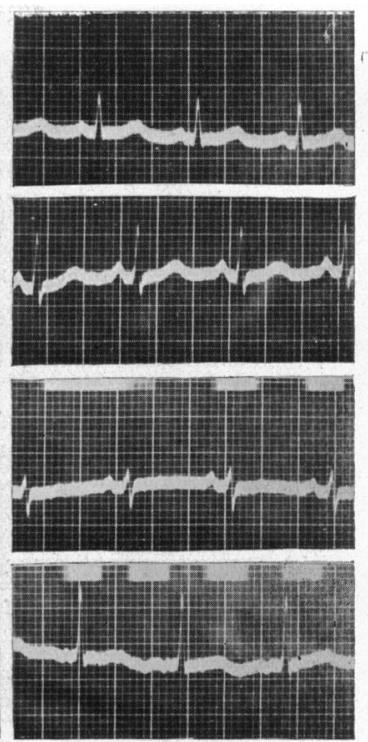

D

Fig. 4.-Case 18. (A) Before treatment. (B) After 7 days of niacin treatment (first trial). (C) After thiamin treatment and plasma infusion. (D) After 5 days of niacin treatment (second trial).

QRS complexes, however, increased (Fig. 4c). The last trial with niacin (5 days of $300 \mathrm{mg}$. by mouth daily) was followed by striking improvement of the cardiogram, which became practically normal (Fig. 4D).

\section{Group III. Cases of Pellagra with no Alterations of the Electrocardiogram}

In the third group comprising 9 cases, the original cardiographic changes were very slight or entirely absent, although the age incidence in this group was even higher than in the first group. Analysing the clinical symptomatology of these patients, it became evident that the outstanding sign was the pellagrous dermatitis, the visceral deficiency manifestations being either very slight or entirely absent. All these patients were ambulatory and visited the out-patient department because of the skin changes. Some of them complained of burning sensation in the tongue and lips. It seems thus that the heart in pellagra is affected mainly in cases in which other visceral organs, such as the brain, stomach, and intestines, show clinical evidence of involvement. When skin changes alone are present in pellagra alterations in the cardiogram may not occur.

\section{COMMENT}

The only vitamin deficiency known to be associated with cardiovascular disturbances is that of vitamin $B_{1}$, e.g. beriberi heart disease which is manifested by cardiac enlargement and heart failure. Experimental as well as clinical $B_{1}$ avitaminosis is associated with cardiographic changes which disappear following $\mathbf{B}_{1}$ administration. The electrocardiogram was also found frequently changed in pellagra. Since in deficiency diseases in man several factors of the vitamin B complex may be lacking simultaneously, the presence of cardiographic changes in pellagra was attributed to $B_{1}$. Feil (1936) in a study of 38 cases of pellagra found 19 with abnormal cardiograms, chiefly concerning the final deflection of the ventricular complex; in some instances, they returned to normal with recovery. The conclusion drawn by this author was that pellagra and beriberi apparently affect the heart physiologically in much the same way. Porter and Higginbotham (1937), on the other hand, found no characteristic changes in endemic pellagra and concluded that beriberi and pellagra have no comparable effect on the heart.

The above-mentioned observations were made before the introduction of niacin in the treatment of pellagra. 
Mainzer and Krause (1940), found a high incidence of abnormal cardiograms in pellagrins in Egypt, but believed that these changes were not characteristic of pellagra and that their occurrence was not sufficient to warrant the conclusion that they were caused by a deficiency of niacin. However, they noticed that there was a parallelism between the course of the disease and the cardiographic changes, and that these disappeared rapidly in some cases following niacin therapy. In the first case report of pellagra successfully treated with niacin, Smith, Ruffin, and Smith, (1937) found low upright $T$ waves in all leads; on the seventh day of treatment the $T$ waves had returned to normal.

The cardiac manifestations in pellagra obviously differ from those in beriberi. Observations reported by others as well as by ourselves clearly show that the heart in pellagra is not enlarged; its size is normal or frequently subnormal: Obvious disturbances of cardiac function and heart failure have not been found in pellagra as is the case in beriberi heart. In our cases of pellagra with œdema of the lower extremities and ascites there was no evidence of congestive heart failure, the œdema being explained by marked hypoproteinæmia. Vitamin $B_{1}$ had no effect on diuresis in these cases; only the rise in serum proteins was accompanied by an increase of diuresis and disappearance of the odema.

It remained, however, to be shown that the cardiographic changes in pellagra are not due to deficiency of vitamin $B_{1}$. During recent years it has become possible by therapeutic tests with pure vitamins to separate the various symptoms and signs of most of the specific avitaminoses constituting the syndrome of pellagra. In order to eliminate the action of $B_{1}$, some of our cases were put on a vitamin $\mathbf{B}_{1}$ poor diet while receiving niacin. In other cases vitamin $B_{1}$ was given first to establish whether this vitamin had any effect on the clinical condition and on the cardiographic changes. It was thus found that only the administration of niacin resulted in most cases in prompt and striking improvement of the clinical symptoms as well as of the cardiographic changes, showing that these changes in pellagra are due specifically to niacin deficiency.

Our observations seem also to indicate that there is a parallelism between the cardiographic abnormalities and the visceral manifestations of the disease. The most striking changes were seen in patients having lesions in the mouth and mental and gastro-intestinal disturbances, sometimes in the absence of dermatitis. On the other hand, the presence of skin lesions alone in chronic pellagrins without obvious involvement of the visceral organs may be associated with normal cardiograms.

The lack of immediate response to niacin in the two cases in which pellagra was associated with severe hypoproteinæmia is of special interest. In these cases the administration of niacin at first had no effect, either on the clinical signs of pellagra or on the cardiographic changes. A positive effect on both was seen only after restoration of the blood proteins. This lack of response to the specific treatment, as long as hypoproteinæmia existed, suggests that in these cases the hypoproteinæmia interfered with the utilization of niacin. Evidence of an interrelationship between protein intake and niacin utilization was given in the experiments of Sarett et al. (1942), who showed that in dogs there was an inverse relationship between protein intake and niacin excretion. The state of the liver in hypoproteinæmia might be responsible for the lack of utilization of niacin. Evidence of liver damage due to protein depletion in dogs was given by Elman and Heifetz (1941), who showed that the liver cells in these animals become vacuolated and that nearly all of the stainable cytoplasm becomes transparent. It may be assumed that in our cases disturbances of liver function during the state of hypoproteinæmia and hypoalbuminæmia were responsible for the failure of response to niacin. That liver damage actually existed was proved in one of these cases by means of the hippuric acid test. There was at the beginning no excretion of hippuric acid after intravenous administration of $2.0 \mathrm{~g}$. of sodium benzoate. With the restoration of proteins, the excretion rose gradually to $0.65 \mathrm{~g}$., which is practically normal.

The cardiographic abnormalities in pellagra, consisting mainly in alteration of the final deflection of the ventricular complex, are in themselves not specific and their presence does not necessarily indicate pellagra as the cause. Similar changes may occur in beriberi and in organic heart disease, most frequently in arteriosclerotic coronary artery disease. Only the fact that in pellagra these changes are reversible and disappear or improve after niacin admin- 
istration, proves conclusively that they are caused by niacin deficiency and hence are a part of the pellagra syndrome.

The question naturally arose whether treatment with niacin has a similar effect on the cardiographic changes accompanying organic heart disease; particularly since observations were reported recently that niacin had a beneficial effect on pain in angina pectoris (Neuwahl 1942). In order to clarify this question six patients suffering from arteriosclerotic heart disease were selected. These patients showed depression of the S-T segment and flattening or inversion of the $\mathrm{T}$ wave in at least two limb leads. There was no history of recent cardiac events to account for these changes. These patients were given niacin for a period of 8 to 10 days and this medication had no effect whatsoever on the cardiograms.

The changes seen in pellagra can also resemble those present in myxœdema, namely flattening or absence of the $T$ waves, and lowering of the voltage of the ventricular complexes. Even the heart rate in pellagra may occasionally be as low as in myxœdema. The myxœdema heart and the abnormal curves in this disease are known to be specifically affected by the administration of thyroid extract. There was, however, a possibility that niacin might also improve the pattern in myxœdema by influencing the metabolism of the heart muscle or by improving the circulation in the heart. Three cases of myxœdema with low basal metabolic rates and characteristic cardiographic changes were given niacin during 6 to 8 days before thyroid treatment. In all these cases niacin in the usual doses had no effect on the curves, which became normal only after thyroid medication.

The specific action of niacin on the cardiogram in pellagra could be explained in the first place by its effect on the coronary circulation. Niacin is known to produce vasodilatation of the skin as indicated by increased temperature and flushing in various parts of the body after administration of the drug. It is doubtful, however, whether the blood vessels of the visceral organs are at all affected by niacin. Investigations (Lomann et al., 1941) have shown that the blood flow through the brain is hardly increased by this substance, although the pial vessels were found to be dilated (Moore, 1940). Furthermore, the vasodilatory action of niacin is transient in character; flushing of the skin usually disappeared within half an hour. According to the studies of Bean and Spies (1940) and our own observations, niacin has no immediate effect on the cardiogram. In several of our cases of pellagra cardiograms were taken before and immediately after the intravenous administration of $50 \mathrm{mg}$. of niacin and no reversal of the pathological changes was noted. The mode of action of niacin on the heart can hardly therefore be sought in its vasodilatatory effect on the coronary vessels. It seems more likely that the influence of niacin on the electrocardiographic changes in pellagra is due to some more fundamental action.

Cardiographic changes due to niacin deficiency are mainly manifested by alterations of the $\mathrm{S}-\mathrm{T}$ segment and the $\mathrm{T}$ wave. Inasmuch as metabolic changes in the heart muscle are reflected in the $T$ wave (anoxemia, thyroid deficiency, and avitaminosis $B_{1}$ ), any factor affecting the metabolism of the heart muscle may also affect the character of the $\mathrm{T}$ wave. According to McLeod (1938), the prolongation of the recovery period of cardiac muscle with a delay in the oxydation of the products of metabolism, is one of the factors responsible for the lowering of the $T$ wave. It is suggested, that the changes in the $T$ waves produced by niacin deficiency may also be of metabolic origin. Niacin is the chemically active fraction of the coenzymes which are essential for the intermediate metabolism of carbohydrates. Axelrod, Spies, and Elvehjem (1941) found a marked diminution of coenzyme I in the striated muscle of human subjects, deficient in niacin, and assumed that the coenzyme content may affect the ability of the human muscle to carry out its oxidative function. It seems logical, therefore, that the coenzyme deficiency also results in an altered metabolic state of the heart muscle. This view is further supported by the fact that the changes are reversible, i.e. they disappear after the administration of niacin.

\section{SUMMARY}

The effect of niacin therapy on the cardiographic changes in 27 patients suffering from pellagra was studied. In 16 of them, with pronounced visceral manifestations of the disease, the response to niacin was prompt; the cardiogram improved or returned to normal after 
several days of treatment. In some cases thiamin was given without any effect; these cases responded promptly to subsequent niacin treatment. In two cases complicated by severe hypoproteinæmia, the response to the first trial with niacin was slight or absent. Only after restoration of blood proteins was the effect of niacin on the cardiographic changes observed. In 9 cases which only had skin lesions no cardiographic abnormalities were found and no changes followed treatment.

\section{REFERENCES}

Axelrod, A. E., Spies, T. D., and Elvehjem, C. A. (1941). J. Biol. Chem. 138, 667.

Bean, W. B., and Spies, T. D. (1940). Amer. Heart J., $20,62$.

Elman, R., and Heifetz, C. I. (1941). J. Exp. Med., 73, 417.

Feil, H. (1936). Amer. Heart J., 11, 173.

Lomann, J., Rinkel, M., and Myerson, A. (1941). Amer. J. med. Sci., 202, 211.

Mainzer, F., and Krause, M. (1940). Brit. Heart J., $2,85$.

McLeod, A. G. (1938). Amer. Heart J., 15, 165, 302.

Moore, M. T. (1940). Arch. intern. Med., 65, 1.

Neuwahl, F. J. (1942). Lancet, 2, 419.

Porter, W. B., and Higginbotham, V. (1937). South Med. J., 30, 1.

Rachmilewitz, M., and Braun, K. (1944). Amer. Heart J., 27, 203.

Sarett, H. P., Klein, J. R., and Perlzweig, W. A. (1942). J. Nutrition, 24, 295.

Smith; D. T., Ruffin, J. M., and Gower-Smith, S. (1937). J. Amer. med. Ass., 109, 2054. 